\title{
O jornalismo de Barbosa Lima Sobrinho
}

\author{
Alexandro Kichileski ${ }^{1}$ \\ Carlos Augusto Locatelli2
}

\section{Resumo}

Barbosa Lima Sobrinho é um dos mais influentes autores e figuras públicas do Brasil no século XX, colaborando no pensamento e na formação do Jornalismo tanto nas redações e no ensino superior quanto na política e na sociedade. Este artigo apresenta uma revisão das principais contribuições teóricas do autor sobre o jornalismo e sua cooperação na construção, manutenção e desenvolvimento social da sociedade moderna, a partir de sua obra principal, o livro O Problema da Imprensa (1923) e do artigo Justiça Social e a Imprensa (1982). Barbosa Lima apresenta diversas reflexões originais, principalmente quanto à vinculação do jornalismo com questões políticas mais amplas, como o espaço público, o desenvolvimento nacional e a justiça social. Junto com seu otimismo normativo e altruísta sobre a função social da imprensa, suas unidades de análise permanecem contemporâneas e promissoras para se compreender o jornalismo e sua relação com a sociedade brasileira hoje.

Palavras-chave: Barbosa Lima Sobrinho. Jornalismo. Opinião Pública.

\section{Abstract}

Barbosa Lima Sobrinho is one of the most influential authors and public figures in Brazil in the 20th century, collaborating in the thought and formation of journalism in both newsrooms and higher education as well as in politics and society. This

\footnotetext{
${ }^{1}$ Formado em Turismo e Ciências Sociais pela Universidade do Contestado. Especialista em Ensino de Sociologia pela UNICENTRO e mestrando em Jornalismo pela Universidade Federal de Santa Catarina. E-mail: alexandrokichileski@gmail.com

2 Doutor em Comunicação e Informação pela Universidade Federal do Rio Grande do Sul (2011). Professor do Departamento de Jornalismo da Universidade Federal de Santa Catarina. E-mail: ocatelli.jor@gmail.com
} 
article presents a review of the author 's main theoretical contributions on journalism and his cooperation in the construction, maintenance and social development of modern society, from his main work, 0 Problema da Imprensa (1923), and the article Justiça Social e Imprensa (1982). Barbosa Lima presents several original reflections, mainly regarding the linkage of journalism with broader political issues, such as public space, national development and social justice. Along with his normative and altruistic optimism about the social function of the press, his units of analysis remain contemporary and promising to understand journalism and its relation with Brazilian society today.

Keywords: Barbosa Lima Sobrinho. Journalism. Public Opinion.

\section{Introdução}

O artigo tem por objetivo apresentar as colaborações do jornalista e intelectual Barbosa Lima Sobrinho na discussão da consolidação do jornalismo no Brasil. O método utilizado é revisão bibliográfica de sua produção e análise reflexiva de suas percepções acerca do jornalismo. Inicialmente apresenta-se uma breve biografia do autor, de modo a contextualizar sua obra, e, em seguida apresenta-se uma revisão das principais contribuições teóricas sobre o jornalismo e sua cooperação na construção, manutenção e desenvolvimento social da sociedade moderna, a partir de sua obra principal, o livro $\mathrm{O}$ Problema da Imprensa (1923) e do artigo Justiça Social e a Imprensa (1982).

Alexandre José Barbosa Lima Sobrinho nasceu em Recife no ano de 1897 e tornou-se uma das figuras públicas mais importantes do século $X X$ no Brasil. Sua formação começa na família, onde recebeu forte influência de seu tio, Alexandre José Barbosa Lima, ex-governador do Estado de Pernambuco e ex-aluno de Benjamin Constant. Portanto, Barbosa Lima Sobrinho recebe uma formação política focada na teoria positivista, distanciando-se da perspectiva do seu tio, ao olhar com severidade e ressalva o liberalismo econômico. Nascido no contexto do que a história política convenciona chamar de Primeira República, ao qual o principal foco está na manutenção do poder dos grandes fazendeiros, sobretudo dos estados de São Paulo e Minas Gerais. Formou-se em Direito na Faculdade de Recife, em 1917, e nomeado promotor público substituto enquanto escrevia suas crônicas para o Jornal de Recife, também colaborou com artigos para o Diário de Pernambuco, Jornal Pequeno, A Gazeta e Correio do Povo, Revista Americana, Revista de Direito e Jornal do Comércio. 
Após ver o concurso de professor de Direito ser cancelado por um juiz que beneficiou seu próprio filho e sem perspectivas profissionais, Barbosa Lima Sobrinho desembarca no Rio de Janeiro em 1921 para trabalhar com o Jornalismo. Trabalhando na redação do Jornal do Brasil, com 27 anos é promovido a redator chefe e aos 30 anos assina a coluna Coisas da Política. Em 1923, publica o livro Problemas da Imprensa, considerado hoje um clássico do jornalismo. Sobrinho viveu de perto a Revolução de 1930 atuando como articulista político e todos os grandes momentos da política brasileira nos anos seguintes. Foi Presidente do Instituto do Açúcar e do Álcool (1938-1945) dentro do regime autoritário de Getúlio Vargas, deputado Federal e governador do Estado de Pernambuco (1948-1951). Teve um papel importante particularmente a partir do golpe de 1964, quando atua na vida pública através da Associação Brasileira de Imprensa (ABI). Em 1974, candidata-se a vice-presidente da República, em 1974, ao lado de Ulisses Guimaraes, e atua em movimentos contra a ditadura militar como o Diretas já. Após a redemocratização, apoiou o Impeachment do Fernando Collor de Mello e foi um grande crítico do processo de privatização empreendido pelo governo do Fernando Henrique Cardoso. (MENDEZ, 1999). Paralelamente, feita essas considerações biográficas, estamos diante um intelectual com uma produção vasta em diversas áreas, a saber: Literatura, Economia, Política, Direito, História. Portanto, para fins deste artigo faz-se necessário um recorte específico, em torno de trabalhos de Barbosa voltados à Imprensa ou Jornalismo: o livro O problema da Imprensa e um artigo publicado a pedido da Ordem dos Advogados do Brasil intitulado de Justiça Social e a Imprensa.

\section{O Problema da Imprensa}

Publicado em 1923, O Problema da Imprensa é considerado a principal obra do Barbosa Lima Sobrinho referente ao jornalismo. Dividido em 26 capítulos, apresenta uma visão histórica da constituição do Jornalismo, bem como seu surgimento e existência dentro do contexto sociopolítico brasileiro. Na edição aqui analisada é a mais atualizada, de 1997, publicada pela Editora USP numa coleção denominada Clássicos do Jornalismo Brasileiro. Para melhor compreender a profundidade e a importância desse autor, apresenta-se uma síntese desse livro, afinal é a base do seu pensamento no tema e 
sobretudo de sua reflexão sobre a imprensa e seus desdobramentos sociais. Importante ressaltar que os anos de 1920 representavam no Brasil os primeiros passos da República,

amparada sobretudo pelos interesses latifundiários e fortemente organizado pelas oligarquias cafeeira.

Em seu primeiro capítulo, O Desenvolvimento do Periodismo, Barbosa procura reconstituir historicamente a necessidade de comunicação humana, encontrando nas Acta Diurna Populi Romana, instituída por César, na Roma Antiga, uma forma de divulgar os fatos que envolviam os governantes. Havia também entre os romanos grupos de pessoas cujo objetivo era de falar sobre os acontecimentos, chamados de circuli, que exerciam a função noticiosa daquele contexto. Posteriormente, no feudalismo, as atividades de formação do que compreendemos por periodicismo são estremecidas, somente com as relacciones é que volta a tendência de organização e serviço de informações, sobretudo focada pelas notícias de guerras. O surgimento do que compreendemos por jornalismo se dará pouco a pouco do aperfeiçoamento dessas funções noticiosas existentes.

Conforme o autor, o periodismo vai se desenvolver mais rapidamente a partir do século XVII, surgindo na França com a Gazette de France (1631), Journal des Savants (1664) e oito anos depois o Mercure Galant. Na Inglaterra, com o fim da Corte Estrelada, o jornalismo também conseguiu se desenvolver com maior fluidez. Porém essa imprensa ainda sofria diversos controles pelos governos, fazendo surgir em paralelo as gazetas manuscritas. Estando na clandestinidade essas gazetas menos oficiosas escapavam da severidade oficiosa e levavam a população conhecimento de eventos contemporâneos. $O$ fim das gazetas manuscritas se dará quando os jornais conseguiam espaço crítico e liberdade de publicá-las, sobretudo na Inglaterra, assim, Barbosa Lima Sobrinho (1997, p. 19) assinala que “(...) a autoridade dos escritores e a moderação de suas críticas conseguiam vencer a severidade do sistema restritivo (...) depois de perdida a sua única razão de ser, desapareceram, sem retorno". Dessa maneira o jornalismo abre espaço para desenvolver sua função crítica e espaço para debater a política e questões pertinentes a administração pública.

Conforme o autor, restrições, perseguições e censuras prévias perduraram por dois séculos e atrasaram a emancipação do jornalismo, que só conseguirá seu progresso quando a opinião pública percebeu sua utilidade, dissipando os rigores absolutistas. É na 
Inglaterra e nos Estados Unidos que essas barreiras serão superadas primeiro, portanto o autor assinala que a liberdade de imprensa só se constituiu efetivamente com as liberdades individuais, com a elevação do nível da democracia e da cultura. Porém, ele é taxativo ao dizer que "a liberdade de imprensa não foi um favor dos governos, mas uma conquista da própria imprensa, que só a obteve com o apoio da opinião pública e o desenvolvimento das liberdades individuais" (BARBOSA LIMA SOBRINHO, 1997, p. 24).

No segundo capítulo, O Atual Poder do Jornalismo, Barbosa Lima Sobrinho constata a mutabilidade que a imprensa sofreu, sobretudo em sua transformação em quarto poder. Esse quarto poder, no entanto, não seria complementar, mas capaz de influenciar todos os outros, pois tem o poder de formar a opinião pública. É nesse aspecto que reside a grande força do jornalismo, em sua capacidade de formar a opinião pública sobre os mais diversos assuntos. Por mais que tenha esse poder, o autor ressalta que a imprensa por vezes não conseguia escapar das medidas reguladoras e que mesmo as constituições proclamem por liberdade, poderia surgir limitações práticas. "Nunca houve para a imprensa um regime de liberdade absoluta, desde que os seus excessos sempre se conceituaram como criminosos e passíveis de penalidades" (BARBOSA LIMA SOBRINHO,1997, p.28).

A noção de liberdade de imprensa é vista não como a estrutura para se falar o que quiser, mas sim como ausência de censura prévia. Todos os escritores têm liberdade para publicar, mas não são imunes a processos de difamação e injúria. O ponto paradoxal é delimitar as medidas restritivas e abuso de imprensa. Dessa maneira, pensar o problema da imprensa é pensar sua regulamentação ou seu trato jurídico.

É por isso que em seu terceiro capítulo, As Leis e a Imprensa, é feito um debate sobre como se deu as doutrinas na regulamentação da imprensa. Após a censura prévia ser banida, países buscaram dispositivos capazes de responsabilizar a imprensa sobre os excessos cometidos, havendo, dentro dessas doutrinas dois grandes grupos, ordinário e especial. $\mathrm{O}$ ordinário seria, como o modelo inglês, aquele que não difere em seus códigos penais, ou seja, um crime executado por um indivíduo verbalmente e a imprensa, a punição e os dispositivos jurídicos são o mesmo. A respeito de uma regulamentação específica para a imprensa. Barbosa Lima não toma partido por nenhuma das duas prerrogativas e observa as limitações tanto do modelo inglês, quanto pelo engessamento 
jurídico. É preciso que as leis acompanhem a marcha da época, sejam repensadas quando se exige uma necessidade púbica.

No capítulo O Jornalismo e a Violência de Linguagem, Barbosa Lima ressalta os excessos de virulência que por vezes a imprensa usa para publicar as notícias, seja vasculhando a vida privada, seja utilizando ironia e sarcasmo. Cita o caso da Inglaterra, onde a linguagem se sobressaia de maneira mais educada e não se limitando as questões políticas (que tendem a ser acaloradas), mas apresentava informações estatísticas, financeiras, comerciais, enfim, uma imprensa com ares mais objetivo. Importante observar que Barbosa Lima Sobrinho ignora a realidade dos tabloides, focando na produção jornalística dos jornais tradicionais ingleses. Porém, a violência não é um desvio da imprensa, mas uma tendência universal do jornalismo de seguir a psicologia popular, afinal, como o autor constata, "o jornal se faz para o povo e precisa por isso falar a linguagem apropriada ao elemento a que se dirige" (BARBOSA LIMA SOBRINHO,1997, p.41).

Para um texto escrito originalmente em 1923, Barbosa Lima Sobrinho articula uma reflexão bastante densa sobre a mutação do jornalismo diante do processo de industrialização. Por isso em $O$ Industrialismo na Imprensa é ressaltada a transição do jornalismo enquanto um sacerdócio, um papel romântico motivado por transformações políticas e sociais para um jornalismo voltada ao lucro. Assim, diante da modernização sofrida pela imprensa, "o artigo político quando muito conservou a primeira coluna; mas em redor, como leitura de maior sensação, se foi distribuindo e colocando o noticiário" (BARBOSA LIMA SOBRINHO, 1997, p.44). Todo esse progresso trouxe a necessidade de um orçamento vultoso. Como provocação interessante, Barbosa Lima Sobrinho ressalta que "a imprensa procurou servir as tendências populares, em vez de as orientar, como acreditava possível, na sua ingênua confiança, o jornalismo romântico" (BARBOSA LIMA SOBRINHO, 1997, p. 45).

O jornal pobre, diante das novas tecnologias vai desaparecendo e essa industrialização crescente fomenta o grande noticiário dos jornais e os serviços de reportagens, dessa maneira criou-se métodos profissionais e as novidades vieram em primeiro lugar, depois os anseios políticos. No caso do Brasil, Barbosa Lima Sobrinho é taxativo: "A grande imprensa do país cada vez mais tende a tornar-se propriedade de milionário" (BARBOSA LIMA SOBRINHO, 1997, p. 48). Por fim, se nas fases iniciais o jornalismo aproximava-se das articulações filosóficas, literárias e políticas, com a 
industrialização passa-se a valorizar a agilidade da escrita e a supervalorização da imprensa em empresa de negócio.

Ao buscar compreender Os Fatores de uma Boa Imprensa, Barbosa Lima assinala a diferença entre um modelo de jornal mais politizado e um jornal voltado ao lucro, um jornal com uma linguagem mais lapidada $e$ outro com uma linguagem rude/sensacionalista. A "imprensa reflete a coletividade a que se dirige" (BARBOSA LIMA SOBRINHO, 1997, p.55), sobretudo a que está apostando no tino comercial, que pela busca de lucro procurará satisfazer as paixões populares. A margem do lucro afasta os jornais comerciais da política, tentando assinalar seu caráter de empresa e/ou aquele que apenas descreve os eventos ocorridos. "O jornalista, no regime atual, não tem garantias. Ele vive à mercê do proprietário do jornal e se acha forçado a dar à folha em que trabalha não só seu esforço pessoal como o sacrifício de sua sinceridade [...]" (BARBOSA LIMA SOBRINHO, 1997, p.56).

Para pensar os excessos do jornalismo Barbosa Lima Sobrinho aposta na capacidade de repensar a cultura moral do povo, ressaltando os limites das leis escritas. Mas a existência de um freio legal é pertinente para atenuar a violência. Por isso o capítulo O Valor de um Freio Legal é importante, sobretudo diante um jornalismo imoderado onde acabamos caindo em um círculo vicioso "porque a imprensa virulenta influi sobre o espírito público, perturba a difusão da cultura equilibrada, estorva a existência de políticos serenos" (BARBOSA LIMA SOBRINHO, 1997, p. 58). Por isso é útil a existência de uma legislação regulamentadora da imprensa.

No capítulo A Liberdade de Opinião, o autor trata sobre como a ideia surgiu com as revoluções individualistas e, durante a história da humanidade, pensar e expressar reflexão diferente poderia conferir um perigo eminente, como foi a morte de Sócrates ou ainda a condenação de Galileu. Porém esse otimismo individualista, proposto pelo liberalismo, começa entrar em crise no século XX, sobretudo com a supressão do indivíduo diante projetos coletivos, sejam eles dentro do regime capitalista como o caso do Mussolini (e para um texto de 1923 conseguiu alertar para ascensão do nazi fascismo posterior) seja em um regime socialista como o caso soviético. "Infelizmente, aquele Estado libérrimo em que cada um gozava da faculdade de expandir os seus pensamentos, não se acomoda nos tempos que passam" (BARBOSA LIMA SOBRINHO, 1997, p. 67). Pensamos que há um otimismo exacerbado no individualista, sobretudo ao podenrar o limite da opinião e da liberdade individual dentro das instituições sociais. 
Perceptivelmente, o tema é extremamente complexo, afinal, a liberdade de um cidadão não pode prejudicar o outro indivíduo e a liberdade de imprensa tem que existir como fomento do livre pensamento, desde também que não cometa excessos ou calúnias infundadas contra outrem.

Interessante observar que o otimismo de Barbosa Lima Sobrinho com o liberalismo se dará sobretudo no campo político no decorrer de sua vida, desencantando-se, por outro lado, com o (neo) liberalismo econômico que limitava nações periféricas e lançava o lucro como norte social, suprimindo drasticamente o espírito público/político revolucionário que outrora o liberalismo político representou. Dessa maneira essa tensão é apresentada o papel da imprensa nos processos políticos brasileiro, começando pela Imprensa na Independência.

Barbosa Lima observa que o Brasil foi um dos últimos países do continente americano a ter tipografias, portanto o desenvolvimento da imprensa nacional deve ser sempre observado por esse constante atrasado. Os primeiros jornais surgiram em 1706 em Pernambuco, Rio de Janeiro com direção de Isidoro da Fonseca em 1747 e uma terceira em 1807 em Minas, "mas foram suprimidas por ordem do governo português" (BARBOSA LIMA SOBRINHO, 1997, p.70). Quando D. João fugiu da invasão francesa trouxe consigo caixotes de uma imprensa encomendada na Inglaterra, com isso surgiu a Imprensa Régia em 1808 com publicações oficiais e depois o primeiro jornal aparecido no Brasil chamado de Gazeta do Rio de Janeiro, que mesmo não sendo fonte oficial, estava associada aos interesses da Coroa Portuguesa. Para Barbosa Lima Sobrinho, a agitação para a Independência veio com o Correio Brazieliense, editado em Londres de 1808 a 1822 e considerado como um dos veículos que ajudaram a consolidar a independência do Brasil. Somente em 1821 é que a censura prévia no Brasil foi abolida, facilitando a criação e disseminação de jornais. Acerca da Independência, Barbosa Lima Sobrinho assinala ainda que "não se tinha ideia clara de independência como separação e, sim, apenas como autonomia administrativa (...) A imprensa coube a atuação preponderante" (BARBOSA LIMA SOBRINHO, 1997, p. 74), foi com a disseminação dela que houve encontros e divergências de ideias e amadurecimento de saídas políticas. Como finaliza nesse capítulo, "A imprensa, pois, agiu nos fatos da independência como um de seus artífices poderosos. Sem a imprensa, a independência não teria sido possível, nem tão cedo, nem tão facilmente" (BARBOSA LIMA SOBRINHO, 1997, p. 74). 
Após o processo de independência, a perseguição aos jornalistas continuaria com uma nova roupagem, que seria resguardar os interesses do Império, tanto que o português José Soares Lisboa, diretor do jornal Correio do Rio de Janeiro teve que sair do Brasil. José Bonifácio publica o Tamoio visando, desde o início, combater os portugueses. Nesse tempo o jornalismo se apaziguou, restando os escritos políticos do Visconde Cairu e os artigos do Diário Fluminense e do Espectador, esses dois jornais com maior moderação política.

O capítulo Ditadura da Opinião mostra como os ânimos e o sentimento anárquico estava deixando o país, politicamente, numa situação extremamente vulnerável. Dentro dessa atmosfera política diversos setores da sociedade tentaram organizar, surgindo dois lados totalmente antagônicos, Partido Caramuru (dentre os principais periódicos desse espectro Absolutista desejando a volta do Imperador destacavam-se o Caramuru, Tempo, Diário do Rio) e o Partido Exaltado (com princípios liberais e ideais republicanos cujos principais periódicos eram o Matraca, 7 de Abril, Sentinela e o Exaltado). Além dessas duas forças radicais havia os Moderados, cujo grande órgão representante era a Aurora Fluminense. Dessa maneira, as lojas maçônicas e outras organizações existentes no processo de independência deram lugar a novas agremiações, partidos e blocos políticos. Dentre duas figuras do período regencial, destacam-se Diogo Feijó e Evaristo da Veiga, esse último grande responsável pela criação da Regência e articulador para superar a anarquia política e tranquilizar o espírito público. Claro que essa visão de Barbosa Lima Sobrinho aproxima-se de uma visão funcionalista e conservadora da sociedade, ignorando que o sentimento anárquico pode ser importante para superar problemas estruturais e históricos.

Em A Imprensa e o Segundo Reinado, ressalta-se que as divergências e a própria "anarquia" foram cessando e um período de paz se consolidando. Feijó firmava, nas palavras de Nabuco segundo Barbosa Lima Sobrinho, a supremacia do governo civil, Evaristo da Veiga ressaltou o princípio monárquico e Vasconcelos reconstituiu a autoridade. Porém para o jornalismo não foi um tempo fácil, os melhores estavam no parlamento e "faltava o interesse popular (...) As ideias que se discutiam pairavam muito acima das aspirações populares e fora do alcance da inteligência (sic) do povo" (BARBOSA LIMA SOBRINHO, 1997, p. 90). O jornalismo caía no esgrimimos acadêmico. Porém observa-se que a evolução das teorias políticas, potencializadas pela imprensa, corroborava para o enfraquecimento constante do poder moderador de Pedro II. "A 
monarquia deixava de ser o centro da vida nacional, reagindo contra as tendências vitoriosas, ou ficando diante delas indiferente" (BARBOSA LIMA SOBRINHO, 1997, p. 91). Coincidem com esse enfraquecimento monárquico o aparecimento, em 1874, de um jornal moderno, barato, sem tendências partidárias, buscando nas notícias recentes, ou "furos", o seu perfil, chamado de Gazeta de Notícias. Publicado por Ferreira de Araújo e depois espaço do agitador pró abolicionismo José do Patrocínio.

Em O Jornalismo e o Movimento Abolicionista é ressaltado o papel da imprensa para a comoção e fomentação da opinião pública. O processo abolicionista teve forte propaganda para seu fim, e a imprensa e a tribuna popular foram os principais meios de formação e consolidação da nova opinião pública. No auge do movimento comícios lotavam praças e teatros. "A influência da imprensa, no abolicionismo, deve ser considerada preponderante, peal continuidade de ação que a faz terrível" (BARBOSA LIMA SOBRINHO, 1997, p. 97), diz Barbosa Lima Sobrinho.

O Jornalismo nos Estados não precedeu a Metrópole. O primeiro veículo aparecido nas províncias data de 1811 na Bahia, que é chamado de Idade de Ouro do Brasil, posteriormente diversos periódicos surgiram em diversas províncias como é o caso do Catarinense em 1832. A imprensa, como visto acima, ajudou a refletir a disputa ideológica no processo de independência e posteriormente a ela, após a queda do Pedro I, multiplicaram-se as folhas combativas. "Em todas essas épocas, na agitada como na pacifica, o jornalismo provinciano se firmou nas suas verdadeiras características: o personalismo e a virtude" (BARBOSA LIMA SOBRINHO, 1997, p. 103). Barbosa Lima Sobrinho ainda argumenta que é possível ver duas classes de jornais, os grandes e os pequenos. Em momentos de agitação política os pequenos se multiplicam como forma de dissipar ideias políticas e ou campanhas e em momentos de tranquilidade política ou sem campanha "mantém-se somente a imprensa de grande formato, que é, por suas responsabilidades e importância, mais moderada e discreta, conquanto às vezes, no calor da peleja, também exagere na linguagem com que discute" (BARBOSA LIMA SOBRINHO, 1997, p.103). Esses jornais, que surgem de acirramento político, utilizam de uma linguagem violenta onde não há limite nos ataques dos adversários.

No capítulo O Jornalismo e o Governo é retratado a relação, e sobretudo a atuação, do governo com a imprensa. Se num primeiro momento da história os governos buscam repreender coercitivamente o jornalismo, após a emancipação desse os governos 
tiveram que mudar de tática, procurando não só a violência mas a subvenção, os prêmios, enfim, os subornos. "O suborno possui maravilhosa eficiência: infiltra-se em vez de atacar, envolve brandamente as criaturas, seduz, comove, convence" (BARBOSA LIMA SOBRINHO, 1997, p. 108). Na história do Brasil essa característica marcou também a nossa política. $O$ auxilio viria ora por subvenção, opa por pagamento de artigos feitos pelo governo ou ainda por favores concedidos, "(...) vamos encontrar nas subvenções à imprensa um dos grandes males do Regime. Há folhas que se fundam exclusivamente para conquistar dinheiro dos cofres públicos" (BARBOSA LIMA SOBRINHO, 1997, p. 112). Uma das causas dessa realidade seria a falta de um jornalismo de partido que acaba forçando o governo processo de subvenção aos grupos tidos como neutros e/ou objetivos.

Muitos ressaltam, exageradamente, os defeitos da imprensa, como se ela apenas disseminasse o mal, a discórdia, aí o questionamento essencial do capítulo Defeitos e Virtudes da Imprensa: "Será que o jornal agrava ou intensifica, esses defeitos humanos?" (BARBOSA LIMA SOBRINHO, 1997, p. 116). Eis que a resposta do Barbosa Lima Sobrinho é que não. Afinal, sobre a intolerância "certamente dela sofreu mais a humanidade antes que aparecesse a imprensa (BARBOSA LIMA SOBRINHO, 1997, p.116). O jornalismo, apesar de alguns excessos, é um elemento que ajuda a civilização no processo de educação. As campanhas liberais e as mudanças políticas contaram com o jornal para a disseminação das ideias. "O jornal fiscaliza o governo; serve-lhe de freio e estorva a desonestidade" (BARBOSA LIMA SOBRINHO, 1997, p. 118). O jornal seria, diante nossa fraquíssima educação democrática, aquele que usa da sua força para conter pretensões autoritárias/ditatoriais. Barbosa Lima Sobrinho deposita na Imprensa, frente as insuficiências dos meios legais, aquele dispositivo que limitaria o autoritarismo. A primeira legislação da imprensa se dava pela censura prévia. Estabelecendo, em 1808, um decreto nomeado os censores régios. Somente em 1821 é que a censura prévia foi suprimida, porém na prática as repressões continuaram a existir. Após a censura prévia os autores/editores é que seriam responsáveis pelo que foi dito, tornando-se proibido o anonimato das publicações. A primeira Constituição brasileira não votou nenhuma lei definitiva a respeito da imprensa, mas deixava claro em seu artigo 13 que os escritos não seriam censurados nem antes nem após as publicações, salvos os casos em que a lei apontar. 
No século XX, com a vitória da URSS, surgiu uma legislação com o intuito de combater o anarquismo, tendendo pela defesa da organização social em vigor (Decreto 4269/1923) atingido os delitos praticados inclusive pelos meios publicitários. Com a Revolução de 1930 buscou-se ter uma reação liberal, porém derrubada pelo Estado novo e retornada a partir de 1953, com o retorno do regime democrático. O golpe militar deu origem a leis autoritárias e após a redemocratização houve a busca da remoção do que era chamado de "entulho autoritário. Barbosa Lima Sobrinho encerra o capítulo Nosso Regime Legal ressaltando que, "se manifestou corrente hostil à existência de uma lei de imprensa, entendendo que bastaria subordinar a atividade jornalística aos termos de um Código Penal" (BARBOSA LIMA SOBRINHO, 1997, p. 129).

Em Ideias de Reformas é descrito todas as tentativas de pensar uma lei de imprensa. Sobretudo uma lei de imprensa eficaz. No caso brasileiro permaneceu a contradição da questão do anonimato e apesar dos debates vigorosos, na prática, as leis voltadas à imprensa permanecem distorcidas.

A necessidade de uma lei de imprensa se faz, sobretudo por excelência política. Porém, dependendo o contexto essa lei é apenas um dispositivo para ressaltar o estado de sítio. A busca de uma lei de imprensa no Brasil veio pelo Partido Republicano Paulista no ano de 1922 e tal projeto destruía qualquer possibilidade de jornalismo independente, exaltando radicalmente a necessidade de assinatura de quaisquer notícias publicada. Por isso no capítulo A Campanha de 1922 e seus Projetos travou debate a respeito dos temas envolvendo a imprensa, mas a supressão do anonimato não foi adiante e a questão do direito de resposta fechou de maneira aceitável.

Em Uma Lei de Imprensa e a Constituição passa basicamente pela questão do anonimato, que no caso brasileiro venceu a percepção da assinatura para os artigos. Dentro dessa concepção não haveria crimes da imprensa, mas apenas abusos disseminados pelos veículos. Na Constituição de 1891 não era impedido estrangeiro dirigir ou gerir jornais publicados no Brasil, porém, o anseio por uma Nacionalização da Imprensa se inicia a partir da Constituinte de 1934 pelo Governo provisório. A partir dessa a nacionalização da imprensa passou a existir nos textos constitucionais de 1937, 1946, 1967/69 e debatida também na Assembleia Constituinte de 1988. Para Barbosa Lima Sobrinho haveria dois tipos de nacionalismo, um dominante pelo espírito positivista e outro que de fato busca consolidar os interesses nacionais. O primeiro é visto na Ditadura 
Militar que puniu todos os militares envolvidos na campanha do 'Petróleo é nosso', e o outro, defendido pelo autor, é o que busca uma imprensa que pense de fato a questão nacional.

Apesar dos limites das classificações conceituais da injúria, difamação e ultraje os delitos comuns privados são quando a imprensa age de má fé com agentes individuais e o delito comum de ordem pública envolve atitudes sobre toda a coisa pública, como a propaganda de ordem subversiva ou segredos de Estado. E é no meio desses excessos que existe duas legislações, apresentadas no capítulo Os Delitos da Imprensa, a saber: legislação comum e legislação especial. Posteriormente Barbosa Lima Sobrinho discorre sobre a tentativa de resolução desse problema em diversos países na busca de compreender a necessidade de existência de uma legislação específica.

E dentro desse processo de análise de legislação é evocada $A$ Questão da Responsabilidade, existindo três sistemas, "o da responsabilidade pessoal, o da responsabilidade solidária e o da responsabilidade sucessiva" (BARBOSA LIMA SOBRINHO, 1997, p. 161). A responsabilidade pessoal torna-se insuficiente sobretudo devido a existência do anonimato. A responsabilidade sucessiva procura um responsável principal. "A lógica desse sistema se resume em obrigar todas as pessoas que interferem na publicação a confessar o seu autor, sob a pena de lhes ser atribuída a responsabilidade completa pelo delito que se contiver no impresso" (BARBOSA LIMA SOBRINHO, 1997, p. 162). Mas, diante da clandestinidade das publicações foi inspirado o sistema de responsabilidade solidária que envolve "todos os que, por qualquer título, participaram cientemente da publicidade de um escrito delituoso, podem ser processados e condenados uns como autores, outros como cumplices" (BARBOSA LIMA SOBRINHO, 1997, p. 165).

O Direito de Resposta é um dispositivo existente na ética do jornalismo. Mas, devido ao não cumprimento de tal recurso por alguns veículos de comunicação isso acabou tornando obrigatório em forma de lei. O direito de resposta é olhado com ponderação pelo Barbosa Lima Sobrinho, sobretudo para não tornar algo que sacrifique a liberdade da imprensa. Já em As Garantias Jurídicas da Imprensa é consolidada as reflexões sobre os limites que as doutrinas jurídicas podem impor ao jornalismo. "Duas questões difíceis e que têm grande importância relativamente às liberdades do jornalismo, dizem com a exceptio veritatis e a utilização do júri, em matéria de delito da imprensa (BARBOSA LIMA SOBRINHO, 1997, p. 177). O autor discorre sobre como o tratamento 
jurídico pode impor restrições à imprensa quando os governos legislam para oprimir a liberdade de expressão e denúncia da imprensa.

Por fim, no último capítulo do livro, A Educação da Imprensa, Barbosa Lima Sobrinho indaga sobre a imprensa ser culpada de todos os males que a acusam constantemente e é taxativo ao dizer que existe jornais maus, mas a imprensa em si é boa. Os excessos da imprensa viriam de parte dela mesma, do governo e da própria população. O público faz das gazetas seu espelho. Do governo surge as subvenções, favores e concessões questionáveis, sobretudo na ausência de uma imprensa de partido. Por fim há a culpa dos próprios jornalistas quando alguns já tem um intuito premeditado nas negociatas. Parte desses problemas é possível, geracionalmente falando, de contornar como educar o povo ou ainda buscar uma estrutura de governo que evite suborno, mas diante de diversas dificuldades vários legisladores buscam criar "para a imprensa uma situação especial, mediante providência que imprensa a atuação daquelas causas de ordem social. Faz-se cair sobre o jornalismo o peso de toda responsabilidade, da própria como da alheia" (BARBOSA LIMA SOBRINHO, 1997, p. 187).

\section{Justiça Social e a Imprensa}

Barbosa Lima Sobrinho escreveu o artigo Justiça Social e a Imprensa a pedido da ABI em 1982. Logo no primeiro parágrafo o autor define a concepção tradicional de Justiça acoplada a seu qualitativo Social. Por Justiça é tradicionalmente compreendido como a vontade de dar a cada pessoa um direito que the cabe, já o qualitativo Social é alcançar não só o direito existente, mas todos que venham dar dignidade a criatura humana. E para efetivar essa justiça social três coisas são indispensáveis: Respeito à liberdade individual, respeito ao poder Executivo, controlado pelo Legislativo e Judiciário e, por fim, respeito a uma justiça distributiva, que viesse reconhecer a necessidade do capital para o trabalho e o trabalho para o capital. "(...) a justiça social abrange todas as providências que visem melhorar a condição do proletário" (BARBOSA LIMA SOBRINHO, 1982, p. 06).

E a imprensa, onde entraria nesse contexto? A imprensa é um dispositivo capaz de (re)afirmar os direitos da pessoa humana e para tal é necessário a liberdade de opinião e consequentemente a liberdade de imprensa. Por outro lado, essa liberdade de imprensa não se fez surtir ao longo da história tão facilmente como visto na discussão de 0 
Problema da Imprensa, afinal, os periódicos surgiram por vezes como privilégios e concessões governamentais, quando não sofria de censura prévia.

O primeiro registro que se teve na busca da liberdade de imprensa sem necessidade de licenças foi com o poeta inglês John Milton, em sua Aeropagítica, discurso proferido no parlamento inglês em 1644. Apesar de não surtir efeito momentâneo, tal acontecimento tornou-se "uma semente poderosa, que o tempo se incumbiria de fazer medrar" (BARBOSA LIMA SOBRINHO, 1982, p. 07). Posteriormente Locke elaboraria um ensaio sobre a tolerância.

Movimentos históricos como a independência dos Estados Unidos ou da Revolução Francesa buscaram maneiras de dar aos homens a liberdade desejada e a busca da dignidade plena. E dentro desse contexto é possível que o "objetivo do jornal era aquele, que também correspondia à existência da sociedade: alcançar a felicidade de todos". (BARBOSA LIMA SOBRINHO, 1982, p. 10). Ou seja, há uma aposta que os periódicos são um dos grandes atores da História, que podem livrar-nos da tirania e são destinados a unir a sociedade e as nações.

Do ponto de vista dos modos de produção, a crescente industrialização levava crer, pela visão funcionalista, em uma cooperação mútua entre capital e trabalho, por isso a aposta da imprensa ser aquela mais fidedigna possível, levando os acontecimentos a todos. Porém na prática a situação da classe operária sempre foi precária, daí o papel da imprensa nas reinvindicações e denúncias das precariedades sociais, como o caso do Cartismo na Inglaterra. "O movimento Cartista foi, assim, uma das primeiras e das mais importâncias vitorias obtidas pela cooperação entre a imprensa e as reivindicações de justiça social" (BARBOSA LIMA SOBRINHO, 1982, p. 15).

Outro ponto importante é reconhecer a influência da ação católica para concretizar a justiça social. E a Ação Católica se manifestava através dos periódicos que traduziam suas pregações, essas que buscavam na caridade a atitude cristã, remetendo as necessidades de justiça social.

No Brasil recém independente, os principais problemas enfrentados será a questão da escravidão e, anteriormente a ela, a da liberdade dos indígenas. O Correio Braziliense teve papel interessante com artigos que denunciavam o regime de escravatura. Um jornalista importante, Sales Torres Homem, ressaltava, em O Maiorista, que o poder da opinião pública assim como extinguiu o tráfico negreiro também iria acabar 
com a escravidão, classificando-a como nefária e desumana. "O que caracteriza a ação e a influência da imprensa é que não consegue dormir sob os louros conquistados nas suas grandes campanhas. A vitória numa causa, serve de estímulo para novos triunfos" (BARBOSA LIMA SOBRINHO, 1982, p. 20).

A questão chave defendida por Barbosa Lima é que as melhores condições sociais necessitam de uma opinião pública bem formada e o jornalismo é uma máquina essencial para a consolidação dessa. Por isso, em sua breve conclusão nesse artigo, Barbosa Lima Sobrinho é enfático ao dizer que "a imprensa é um fator indispensável na luta para a conquista da justiça social” (BARBOSA LIMA SOBRINHO, 1982, p. 21). Mas para isso ocorrer é necessária uma condição essencial de ampla liberdade, tanto de opinião quanto de informação.

\section{Considerações finais}

A releitura de O problema da Imprensa e Justiça Social e a Imprensa permite perceber Barbosa Lima Sobrinho como intelectual e homem público singular a seu tempo. Do ponto de vista de sua contribuição à compreensão pragmática e teórica do jornalismo, suas unidades de análise - e não necessariamente suas análises - permanecem bastante contemporâneas para se compreender o jornalismo e sua relação com a sociedade brasileira, compondo em seu conjunto um modelo analítico bastante robusto para a pesquisa na área.

Entre essas unidades destacam-se (a) o peso dos processos históricos que conformaram a imprensa e o jornalismo, (b) o poder do e sobre o jornalismo, (c) o sentido do arcabouço jurídico-institucional, (d) o papel das estruturas de mercado e padrões de concorrência, (e) a relevância normativa das boas práticas e da ética profissional, (f) o conflito entre liberdade de expressão e o direitos de personalidade, (g) o potencial e os riscos da linguagem; $(h)$ as relações com outros atores socais, especialmente o governo; (i) as relações entre jornalismo e opinião pública. É importante constatar a preocupação intuitiva de zelar pelo Jornalismo como meio de consolidar uma opinião pública consistente e um espírito público democrático e republicano.

Imerso nas discussões de seu tempo, Barbosa Lima foi ainda um homem preocupado com o desenvolvimento do país e seus estudos buscaram compreender as 
características necessárias e capazes de transformar o Brasil em um país forte, independente, com liberdade política e com justiça social. Crítico ferrenho do projeto neoliberal, a partir de uma forte posição católica típica da primeira metade do século $X X$, acreditava que a imprensa tem um papel primordial no desenvolvimento do país e na conformação da vida pública através da Opinião Pública. É portanto um intelectual que colabora para se pensar a esfera pública contemporânea, a partir de um ideal normativo do que o jornalismo pode oferecer dentro dos processos sociais.

E aí está, possivelmente, a maior possibilidade de crítica às suas ideias: o excesso de confiança no papel positivo que o jornalismo e imprensa teriam ao fomentar a consciência social e o bem comum, e, por fim, a própria opinião pública. Como bem assinala Bobbio (2010), opinião pública não significa verdade, na medida que seu consenso não passa por um rigor filosófico ou cientifico, ou seja, opinião representa a doxa e não a espiteme. Logo, se é impossível uma sociedade não construir alguma opinião pública, é necessário refletir os mecanismos que a constroem e seus impactos sobre o movimento dos atores sociais. Imerso nas condições de seu tempo, Barbosa Lima atribui um papel romântico ao jornalismo, cujo ideal político conduziria a sociedade a felicidade ou ao bem comum.

Apesar da restrição ao otimismo e a função "altruísta" da Imprensa moderna, sob um ponto de vista normativo as obras de Barbosa Lima Sobrinho podem servir de referência ao que falta na contemporaneidade: a busca pelo bem comum, a valorização da política como manifestação de transformação da sociedade, o desenvolvimento com justiça social e, claro, uma (outra) Imprensa que valorize a pluralidade do pensamento, que fomente o debate e aprimore, de fato, a Opinião Pública para o bem estar dos cidadãos.

\section{Referências}

BOBBIO, N. et al. Dicionário de política. 13. ed. Brasília: UnB, 2010.

ESTEVES, J. Espaço público e democracia: comunicação, processo de sentido e identidade social. São Leopoldo: Unisinos: 2003.

GOMES, W. Da discussão a esfera pública. In: GOMES, W.; MAIA, R.C. Comunicação e democracia: problemas e perspectiva. São Paulo: Paulus, 2008 
LIMA SOBRINHO, Alexandre José Barbosa. O Problema da Imprensa.

São Paulo: Edusp, 1997.

Justiça Social e a Imprensa. Florianópolis, OAB: 1982.

O Jornalismo e a Literatura: Rio de Janeiro, in: Curso de Jornalismo -

Conferências realizadas na Academia Brasileira de Letras, 1958.

Em Defesa do Interesse Nacional: desinformação e alienação do patrimônio público. São Paulo: Paz e Terra, 1995

MENDEZ, Rosemary Bars. Olhos do Jornalista: O Jornalismo segundo Barbosa Lima Sobrinho. Dissertação (Mestrado em Comunicação Social) -Faculdade de Ciências da Comunicação e da Cultura da Universidade Metodista de São Paulo. São Paulo, 1999.

Recebido em: 11/06/2018

Publicado em: 21/12/2018 